\title{
La Rivière (Isère)
}

Domaine départemental des Écouges, ferme du Rivet

\section{Alain Belmont}

\section{(2) OpenEdition}

\section{Journals}

Édition électronique

URL : http://journals.openedition.org/adlfi/6971

ISSN : 2114-0502

Éditeur

Ministère de la culture

Référence électronique

Alain Belmont, "La Rivière (Isère) », ADLFI. Archéologie de la France - Informations [En ligne], RhôneAlpes, mis en ligne le 01 mars 2007, consulté le 03 mai 2019. URL : http://journals.openedition.org/ adlfi/6971

Ce document a été généré automatiquement le 3 mai 2019.

(c) Ministère de la Culture et de la Communication, CNRS 


\section{La Rivière (Isère)}

\section{Domaine départemental des Écouges, ferme du Rivet}

\section{Alain Belmont}

Identifiant de l'opération archéologique : 229454

Date de l'opération : 2007 (SD)

1 Menés par le LARHRA (UMR CNRS 5190) en juin 2007, les sondages (Fig. ${ }^{\circ} 2$ : Vue générale des sondages du Rivet) ouverts aux Écouges, au sein d'une vallée isolée du nord-est du Vercors, ont mis au jour au lieu-dit Le Rivet et à $1100 \mathrm{~m}$ d'altitude, les vestiges d'une ferme bâtie entre 1657 et 1665, occupée tout au long des XVIII ${ }^{e}$ s. et XIX ${ }^{e}$ s. (Fig. $n^{\circ} 1$ : La ferme du Rivet d'après un plan aquarelle dessiné vers 1776). et entièrement détruite à la suite des combats de la seconde guerre mondiale.

2 Trois tranchées d'une surface totale de $67 \mathrm{~m}^{2}$, précédées par une prospection géophysique, ont montré que cette ferme avait été construite en trois ou quatre phases. La phase initiale comprenait un édifice rectangulaire de $17 \mathrm{~m}$ sur $10 \mathrm{~m}$ divisé en une partie habitation au sud et une partie exploitation au nord, celle-ci comprenant vraisemblablement une grange et une étable. Si sa toiture, en " essendoles » (tuiles de bois), participait d'un mode de couverture économique et traditionnel en pays de montagne, le reste du bâti témoigne au contraire d'une qualité architecturale inusitée dans les simples fermes paysannes du XVII ${ }^{e}$ s. : fondations profondes et soigneusement appareillées, murs édifiés "à chaux et sable », dallage monumental dans la pièce principale, peut-être sorti des ruines de l'ancienne chartreuse des Écouges. D'après les textes d'archives, ce premier bâtiment avait coûté la bagatelle de 1000 livres, soit le prix à l'époque de 15 à 20 maisons de journaliers ou d'artisans. Au cours des deux à trois phases de construction suivantes, intervenues entre la fin du XVIII ${ }^{e}$ s. et la fin du XIXe s., l'édifice initial s'accroît d'un four à pain, d'un hangar et de pièces supplémentaires qui portent son emprise au sol à près de $370 \mathrm{~m}^{2}$, auxquels s'ajoutent encore deux étages à l'intérieur de la partie habitation. Incendié en 1944, ce bâtiment fut rasé en deux temps pour laisser la place, à la fin du XXe s., à une plate-forme en herbes. 
3 Si les sondages n'ont pas rempli leurs promesses en termes de mobilier, les niveaux archéologiques ayant été presque entièrement raclés à la pelle mécanique ou trop soigneusement nettoyés par les anciens occupants, fouilles et recherches en archives ont apporté un éclairage stimulant sur l'intérêt porté par la haute aristocratie du XVII $s$. envers l'activité agropastorale. Loin d'une exploitation vouée à une polyculture vivrière, la ferme du Rivet sert en effet d'appui à l'élevage d'une centaine de bovins, qui paissent durant la belle saison des prairies d'altitude récemment défrichées, et arrosées grâce à une série de retenues d'eau et de canaux. Le lait de ce troupeau est transformé en fromage par des Suisses, probablement pour alimenter un commerce à vaste échelle. Plus qu'à une simple ferme ou " grange », le site du Rivet s'apparente donc à ces haberts dans lesquels les pères de la Grande-Chartreuse pratiquaient un élevage de type grande montagne. Il constitue ce faisant un élément à part entière d'une économie domaniale non pas routinière mais à la pointe des techniques du temps, caractère que l'on retrouve dans d'autres investissements des propriétaires du Rivet, comme la carrière de meules de Quaix-en-Chartreuse ou la fonderie de canons de Saint-Gervais, pour ne citer que des établissements proches. Ce dynamisme économique est d'autant plus remarquable qu'il est l'œuvre de deux femmes : Laurence Frère (vers 1613-1674), épouse d'Antoine du Faure, président au parlement de Grenoble, et sa fille Marie du Faure (1642-1710), épouse de Nicolas Prunier de Saint-André, premier président au parlement et ambassadeur du roi Louis XIV à Venise.

BELMONT Alain

\section{ANNEXES}


Fig. $n^{\circ} 1$ : La ferme du Rivet d'après un plan aquarelle dessiné vers 1776

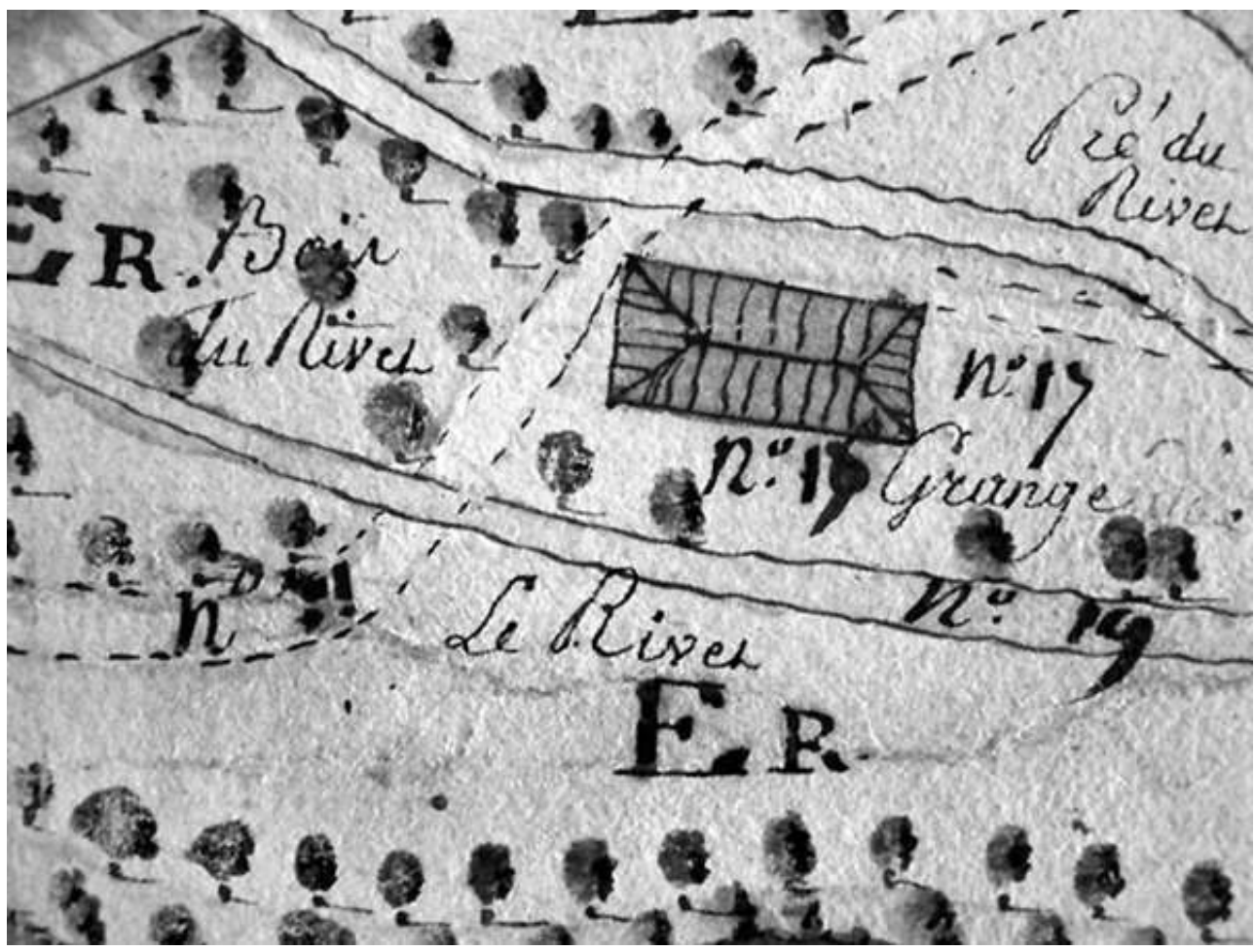

Auteur(s) : Belmont, Alain. Crédits : ADLFI (2007)

Fig. $n^{\circ} 2$ : Vue générale des sondages du Rivet

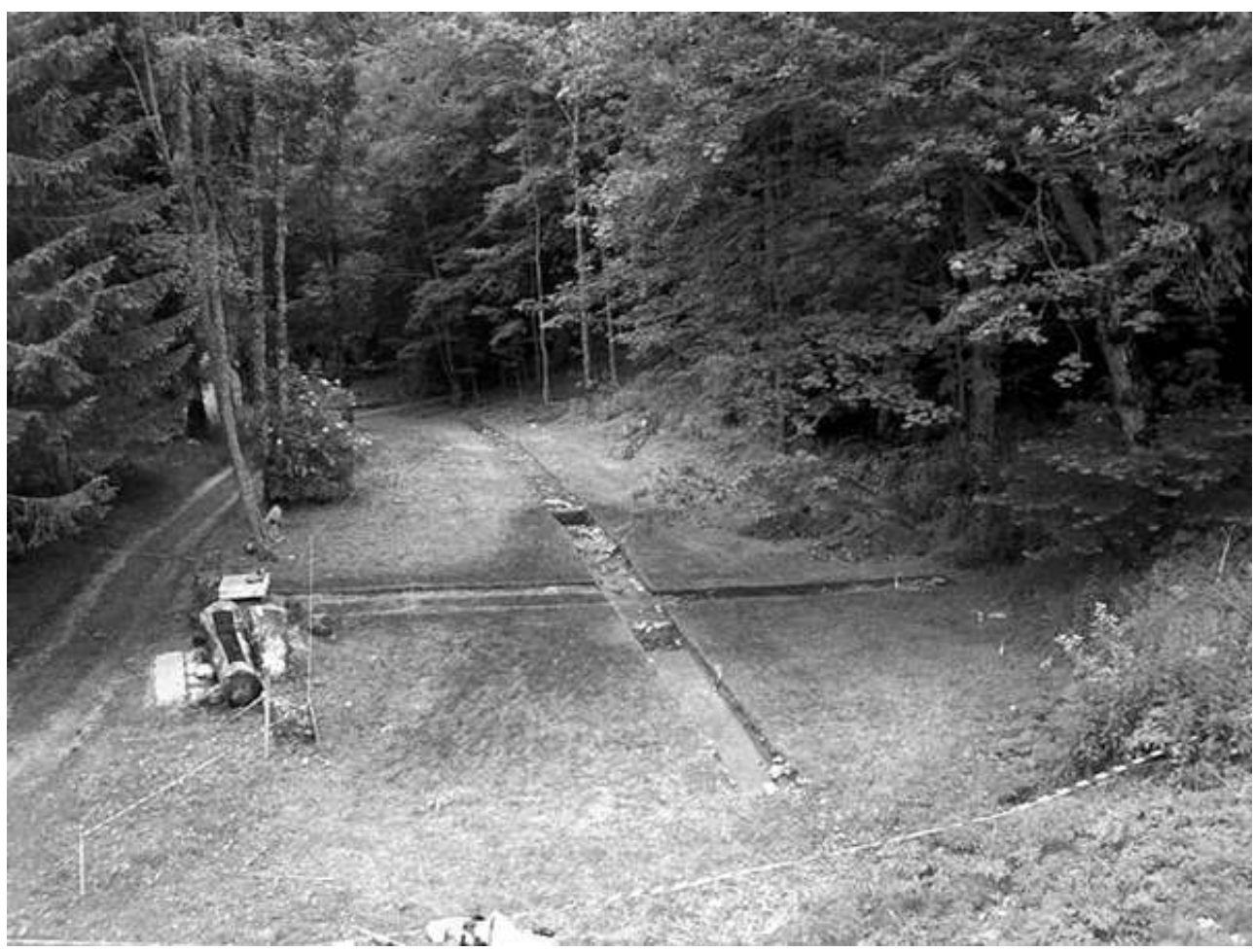

Auteur(s) : Belmont, Alain. Crédits : ADLFI (2007) 
INDEX

Index chronologique : ép. contemporaine, Temps Modernes, XIXe siècle apr. J.-C., XVIIe siècle apr. J.-C., XVIIIe siècle apr. J.-C.

Index géographique : Rhône-Alpes, Isère (38), Rivière

operation Sondage (SD)

\section{AUTEURS}

ALAIN BELMONT

SUP 